\title{
The System of Education in Rural Areas
}

\author{
Radhika Kapur* \\ Pedagogy and Organizational Culture in Nursery Schools, Delhi University, New Delhi, India \\ *Corresponding Author: Radhika Kapur, Pedagogy and Organizational Culture in Nursery Schools, Delhi University, New Delhi, India.
}

Received: April 08, 2019; Published: June 11, 2019

DOI: 10.31080/ASAG.2019.03.0520

\begin{abstract}
The main objective of this research paper is to acquire an efficient understanding of system of education in rural areas. In rural communities, the system of education is in an underdeveloped state. There are scarcities in terms of teaching-learning methods, instructional strategies, transportation facilities, infrastructure, extra-curricular activities and teachers. Lack of these aspects is proving to be impediments within the course of progression of rural education as well as rural communities. Therefore, measures and programs need to be initiated in terms of bringing about progressions in the system of rural education. In the present existence, technology is regarded to be of utmost significance. The use of technology has proven to be advantageous to the implementation of various tasks and activities to a major extent. The main areas that have been taken into account are, problems in rural education, measures to improve rural education, programs formulated by the Government, and recommendations.

Keywords: Education; Facilities; Infrastructure; Programs; Schools; Students
\end{abstract}

Right to education is the primary right of every citizen of India [1]. All the citizens, irrespective of caste, creed, race, religion, ethnicity, gender and socio-economic background have the right to acquire education. The system of education in rural areas is still in a developing stage. The conditions of schools in rural communities are still in a deprived state. In rural areas, the schools do not make provision of adequate infrastructure, amenities and facilities to the students, which are regarded essential to facilitate the acquisition of education in an effective manner. Another major problem is, the number of schools are less, they are located at a distance from homes and children are required to travel to distant places. The teaching-learning methods and instructional strategies that are utilized in making provision of education to the students need to be improved. The students are usually unable to acquire an efficient understanding of the academic concepts and generate better academic outcomes.

In bringing about developments in the system of education, teachers have an important role to play. In rural schools, teachers are not much skilled and qualified. They encouraged students to express their viewpoints, observations and experiences. The main objectives of rural schools are, to ensure that every student re- ceives good quality education, provide assistance to the students to get enrolled in higher educational institutions, provide guidance and support to the researchers to participate efficiently in educational development, implementation of new teaching methodologies and assessment systems and promoting schools towards a stress-free environment [1]. Developments in the system of rural education mainly focuses upon creation of amiable school environmental conditions and utilizing the practices and methods in such a manner that would enhance the educational skills and abilities of the students. When recruitment of teachers takes place, it needs to be ensured that they are well-qualified, experienced and possess a pleasant personality and an approachable nature.

\section{Problems in Rural Education}

The various problems and challenges within the system of rural education have been stated as follows:

- Unsatisfactory Teaching-Learning Methods: The teaching-learning methods that are put into practice in rural schools need to be improved. Research has indicated that due to inefficiency in these methods, students are unable to enhance their academic skills. The students studying the class five are unable to read class three textbooks. This 
shows that teaching-learning methods that are made use of are not put into operation in a well-organized manner. It is the job of the teachers to ensure that teaching-learning methods are efficiently utilized. The teachers employed in rural schools normally do not possess the required educational qualifications and skills that are needed to facilitate learning among students. Hence, lack of skills and abilities on the part of the teachers is a major cause for the implementation of unsatisfactory teaching-learning methods.

- Lack of Transportation Facilities: The schools are located at a distance from homes and lack of transportation facilities is regarded as a major impediment within the course of acquisition of education. The rural schools do not make provision of any transportation facilities for the students, particularly, those residing at a distance. Students, particularly, enrolled in elementary and junior schools need to be dependent upon their family members to take them to schools and bring them back. Whereas, students enrolled in secondary and senior secondary schools, usually arrange transportation facilities for themselves on their own. In some cases, students go to school and return home along with the fellow students and this alleviates the concern on the part of their parents. But when they do not have fellow students, travelling by the same distance, then they usually experience problems in transporting to schools. Hence, lack of transportation facilities is a problem within the course of getting enrolled in schools.

- Lack of Infrastructure: Proper infrastructure enables the individuals to acquire academic skills in an appropriate manner. It includes, furniture, machinery, heating and cooling equipment in accordance to the weather conditions, amenities and facilities. In rural schools, students sit on the floor, as there are not any chairs or desks within the classrooms. When there is lack of furniture, then students may learn, while sitting on the floor. But when there is lack of machinery, technology and equipment, then they are normally are unable to acquire an understanding of the academic concepts in an efficient manner. In some cases, when there are not proper construction of classrooms, then learning may take place in the courtyard or underneath the trees. Hence, lack of infrastructure is regarded as one of the major problems in rural schools.

- Lack of Extra-Curricular Activities: Students belonging to all age-groups and backgrounds take pleasure in the acquisition of education, especially, when there are adequate provision of extra-curricular activities. These include, dance, music, singing, sports, physical activities, role plays and so forth. When the students participate in these activities, then they develop motivation and enthusiasm towards learning. In rural schools, there are lack of extra-curricular activities, which is regarded as a hindrance in making provision of good quality education to the students. In the curriculum and instructional systems, they are only provided adequate information in terms of academic concepts. In other words, there is not any provision of supplemental education.

- Lack of Financial Resources: Financial resources are considered to be of utmost significance within the course of development of the system of education. To make provision of appropriate teaching-learning methods, learning materials, infrastructure, civic amenities and facilities and to bring about improvements in the overall quality of education, it is essential to possess sufficient financial resources. In rural schools, there are shortage of funds, due to which, the individuals are able to make quality education available. In some cases, the school environmental conditions are in a deprived state, as there are lack of furniture, equipment, blackboards etc. Hence, it can be stated that due to lack of financial resources, necessary equipment and materials are not available to the students in enhancing their learning.

- Absence of Competitions and Events: Competitions and events are considered an integral part of education. The competitions are organized with regards to various areas, such as, academics, sports, physical activities, dance, music, singing, role plays, poetry and so forth. Participation in competitions augment the skills and abilities among the students and stimulate their mind-sets towards learning. Furthermore, students are able to develop effective communication skills and put in more confidence among themselves to improve. In rural schools, there are absence of competitions and events. When these are to be organized, then it is vital for the teachers as well as the staff members to possess adequate skills and knowledge. The absence of competitions and events is regarded as the major barrier within the course of acquisition of education.

- Shortage of Teachers: In order to facilitate education, it is essential to recruit qualified and capable teachers. The teachers are vested with the responsibility to provide educational knowledge and concepts to the students to promote their growth and development in an effective manner. In nursery schools, normally all subjects are taught to the students by a single teacher, but in elementary, junior, secondary and senior secondary schools, the teachers are usually specialised in terms of one subject area. The shortage of teachers in rural schools is a major barrier within the course of development of the system of education. It is apparent, when well-qualified, 
skilled and experienced teachers are not present, then the students would certainly experience problems in the acquisition of education.

- Low Income: The teachers in rural schools do not get paid much for their job duties. In other words, their income is insufficient to meet their livelihoods requirements. It has been comprehensively understood that individuals get engaged in employment opportunities to acquire income to sustain their living conditions in a well-organized manner. When the teachers work hard in the implementation of job duties and do not get paid much, then they usually lose interest. They tend to leave their jobs and look for other well-paid employment opportunities. It has been found that individuals do not possess interest and enthusiasm in obtaining teaching positions in rural schools. When they develop interest in teaching, then they usually migrate to urban areas, as schools in urban communities are well-developed, have an improved system of education and teachers are paid well.

- Conflicts and Disputes: Research has indicated that in rural schools, there are occurrence of conflicting situations and disputes among the students as well as teachers and students. Teachers normally depict strictness and stringent behaviour upon students for various reasons, such as, not completing their home-work assignments, low grades in tests and exams, high rate of absenteeism, and so forth. When students experience conflicts and disputes in schools or harsh treatment on the part of the teachers, then they normally drop out of schools, even before their educational skills are honed. On the other hand, when unfavourable situations are observed on the part of the fellow students, then too, students, particularly girls feel vulnerable in attending schools and the ultimate outcome is school drop-out.

- Discriminatory Treatment: The girls are the ones, who experience discriminatory treatment within schools in rural areas. When teachers are teaching a lesson plan and there are organization of any activities, related to it, then boys are given preference. Equal opportunities are not provided to the girls, as they are provided to the boys. Hence, mainly due to this factor, girls are being discriminated against. When there are organization of class tests or assignments, then normally grading takes place on the basis of one's performance. But apart from enhancement of academic skills, students also need to augment their cognitive, intellectual and communicative skills. For this purpose, it is vital for them to participate in various activities and programs that are organized within schools. When girls are not provided with opportunities, then they feel, they are being discriminated against.
Measures to improve rural education

The measures which are required to be initiated to bring about improvements in the system of education have been stated as follows:

- Up-gradation of Teaching-Learning Methods: The teaching-learning methods need to be implemented in accordance to the needs and requirements of the students. The different types of teaching-learning methods are, giving notes regarding lesson plans, making the students read and then provide verbal explanations, providing explanations of the concepts on the blackboards, making the students play the role of characters within the lesson plans, giving practice exercises, organizing tests and so forth. When the teachers make use of different teaching-learning methods, they need to possess efficient skills and ensure students learn adequately. Up-gradation of teaching-learning methods is one of the essential aspects to improve rural system of education. But on the part of the students also, it is vital to pay adequate attention, particularly when they are learning academic concepts.

- Use of Technology: In the present existence, technology has gained prominence in the implementation of various tasks and activities. In education also at all levels, use of technology is rendering a significant contribution in augmenting learning and understanding among students. It is comprehensively used in urban educational institutions, but in rural schools, there is still lack of technology. Therefore, making use of technology in the system of education is regarded important. The various types of technologies, such as, computers, lap-tops, projectors, smartphones, mobile apps and so forth would facilitate understanding of the concepts. The students as well as the teachers make use of internet to enhance knowledge in terms of various concepts. Both central and state governments and non-government organizations are allocating a great amount for the development of Information and Communication Technology (ICT) and rural education [2]. The staff members also make use of technology to carry out the administrative functions. This is common in educational institutions in urban areas. When one has to prepare a document, letter, notice or send messages or information, then technology is made use of to a major extent. Due to lack of technology, the education system in rural areas is experiencing set-backs.

- Organization of Workshops: Workshops are normally organized in urban schools and higher educational institutions on a large scale. They are organized in terms of a particular topic or concept, which students normally find complicated. The main objective of organization of workshop is to make provision of 
knowledge to the students to enrich their understanding. In rural schools, it is vital to organize workshops to facilitate understanding of the concepts among the students, which they find difficult. In workshops, usually professionals are invited from other educational institutions. They deliver speeches, provide information and generate awareness, which enables the students to understand better. Assignments too are provided to the students, with the aim of finding out how much they have learned and understood. Therefore, it can be stated that organization of workshops is regarded as one of the essential aspects to improve the system of rural education.

- Implementation of Extra-Curricular Activities: In schools, apart from appropriate teaching-learning methods and instructional strategies, particularly regarding the academic concepts, it is necessary to implement extra-curricular activities. The provision of extra-curricular activities stimulates the mind-sets of the students and motivate them towards learning and attending schools. The various forms of extra-curricular activities that are considered an integral part of education are, artworks, handicrafts, music, singing, dance, sports, physical activities, role plays and so forth. When students, belonging to rural communities for instance, learn making of artworks, handicrafts, or participate in sports, physical activities or dance and music, then they feel pleasurable and contented. In rural communities, individuals also develop interest in usually any one of extra-curricular activities, and make it a career. They put into practice the activities to even supplement their income.

- Implementing Proper Evaluation Procedures: Evaluation is regarded as one of the essential aspects to find out how much the students have learned and understood. Evaluation procedures help in identifying the flaws and inconsistencies and making improvements. The most common forms of evaluation procedures are giving class and home-work assignments, conducting tests, exams, competitions and so forth. In rural schools, exams are conducted, but the system of examinations is not well-developed. It is essential to put into operation, proper evaluation procedures. The teachers need to ensure that when they complete the lesson plan of any subject, they give class as well as home-work assignments to the students. When the students perform well, then it is understood that they are making use of teaching-learning methods in an appropriate manner. On the other hand, when students experience set-backs, then it is essential to bring about improvements in teaching-learning methods. Hence, implementation of proper evaluation methods would not only facilitate improvements in the performance of the students, but also in the teaching methods.
- Rewarding Students: Rewarding students, particularly when they perform well academically is regarded as an important aspect to improve the system of education. The main objective of education is to lead to effective growth and development of the students. When they get enrolled in schools and work diligently and enthusiastically to enhance their academic performance, then it is vital for the teachers to reward them. Rewards may be in the form of sweets, stationary items, writing appreciative statements on the notebooks and so forth. When the students are given rewards, then they feel pleasurable and motivated towards learning. Research has indicated that through rewards, students feel encouraged towards attending schools on a regular basis and this leads to a decline in the rate of absenteeism as well.

- Providing Adequate Infrastructure: Making provision of adequate infrastructure would render an effective contribution in facilitating not only acquisition of education among the students, but also assisting teachers as well as the staff members to carry out their job duties appropriately. In schools, availability of proper furniture, desks and chairs, heating and cooling equipment in accordance to the weather conditions, machinery, technology, learning materials, such as, blackboards, books, stationary and so forth, would not only augment understanding of academic concepts among the students, but also enable them to feel pleasurable and contented within the school environment. The infrastructural facilities in schools contribute in making the school environmental conditions pleasant and amiable.

- Financial Assistance: Individuals normally feel hesitant in getting enrolled in schools due to financial problems. Therefore, making provision of financial assistance is regarded to be of utmost significance that would encourage enrolment of students in schools. This is made available in the form of scholarships and grants. Scholarships are made available to the students, usually on the basis of their merit. When they perform well in class, achieve good grades, then they are made available scholarships and other forms of financial assistance. Apart from scholarships, the forms of assistance is provided to the students in the form of mid-day meals. The schools provide nutritious meals to the students, so they do not have to be concerned regarding getting meals from homes. The availability of financial assistance provides contentment to the individuals, mainly belonging to deprived and marginalized sections of the society.

- Equal Opportunities: In schools, it is vital to make provision of equal opportunities to girls. These may be in terms of participation in classroom activities or when there are orga- 
nization of any competitions and events. Rural schools are primarily co-ed, i.e. when girls and boys, are enrolled in schools. Hence, it is vital for the teachers to ensure that girls too are treated equally and they should be allowed equal participation opportunities as the boys, especially in the implementation of lesson plans. Another point that is essential to be taken into consideration is, girls should be treated with respect and courtesy. Research has indicated that lack of equal opportunities and discriminatory treatment against the girls also compel them to drop out of schools, even before their educational skills are honed. Therefore, for leading to progress of the schools and enhancement of the system of education, it is necessary to make provision of equal opportunities.

- Organization of Classes for the Parents: In rural communities, parents are in some cases unwilling to get their children enrolled in schools, particularly girls. They possess the viewpoint that girls are meant to acquire training in terms of the implementation of household chores, as they have to eventually get married and go to marital homes. They possess the viewpoint that in their marital homes, they would not be able to make use of their educational skills and abilities. On the other hand, they believe in sending their male children to schools and augment their academic skills and abilities. They feel that male children would acquire employment opportunities and enhance the reputation of their families, when they acquire education. Therefore, to enable the parents to encourage education among girls is necessary not only for development of the system of education, but also overall rural development. Hence, the main purpose of organization of classes for the parents is to enable them to recognize the significance of education for their children and how it can lead to improvements in their overall quality of lives.

\section{Programs formulated by the government}

For promoting the significance of education throughout the country, there has been implementation of the Right of Children to Free and Compulsory Education Act, 2009. It is an act that was introduced to make provision of free and compulsory education to the children, belonging to the age group of six to fourteen years. Several central and state level initiatives have been in operation from the early 1980s. The major objectives include, increasing enrolment of girls, enhancement of academic outcomes, reinforcement of community involvement, improving teaching-learning methods and instructional strategies and augmenting the skills and abilities among the teachers by making provision of in-service teacher training [1]. Some of the programs have been stated as follows: [1].

\section{Lok Jumbish Project (LJ)}

The Lok Jumbish (LJ) project has 75 blocks, covering approximately 12 million of the population. LJ project works in co-ordination with the government agencies, teachers, non-government organizations, elected representatives and other individuals, with the aim of promoting universalization of primary education. The seven guiding principles are, a process rather than a product approach, partnerships, decentralized functioning, participatory learning, integration with the mainstream education system, flexibility of management and forming multiple levels of leadership, committed to quality and mission mode. LJ progressed close to about two decades of work in the areas of primary education. The functions were carried out both by the Government and voluntary sectors. The Shiksha Karmi of Rajasthan, could be considered as the indicators of the programs within the state [3].

\section{Shiksha Karmi Project (SKP)}

The Shiksha Karmi Project (SKP) is being implemented since 1987. The assistance is available from the Swedish International Development Cooperation Agency (SIDA). It aims at the universalization of elementary primary education in the remote villages of Rajasthan. Special emphasis was put upon girls. The SKP was based upon the advanced, economical and practical approach. It was originally developed in the Silora Block by the Social Work Research Centre (SWRC), a voluntary group in Tilonia and the Government of Rajasthan (Chapter - II. Primary Education in Madhya Pradesh and Rajasthan, n.d.). SKP has established the Village Education Committees (VECs) in 2000 villages to promote community involvement in primary education and promote village level planning. Non-formal classes are also organized by SKP, which are known as preher pathshalas. The education among girls is encouraged by the organization of angan pathshalas in three blocks. The program at present covers $1,50,000$ students in 1,785 schools and 3,250 preher pathshalas, involving more than 4,271 shiksha karmis.

\section{Sarva Shiksha Abhiyan (SSA)}

The major objective of this program is all children, belonging to the age group of six to eleven years, should complete primary education by 2007 . Whereas, all children, belonging to the age group of six to fourteen years should complete eight years of schooling by 2010. Special emphasis is put upon education of girls, scheduled castes, scheduled tribes and children with special needs. The SSA centres are mainly established in those areas, which do not have any schools. Special girl oriented programs include, girl education at elementary level, National Program for Education of Girls at Elementary Level (NPEGEL), Kasturba Gandhi Balika Vidyalaya (KGBV) and Mahila Samkhaya Scheme. 


\section{District Primary Education Program (DPEP)}

This program was initiated in 1994 with the main objective of universalization of primary education. The main features of this program are, universal access, universal retention and universal achievement. It aims that primary education should be accessible to each and every child of school going age. Once the child gets enrolled in school, he should be retained. The major components of this program are, construction of classrooms and new schools, opening of non-formal schooling centres, establishing early childhood education centres, recruitment of teachers and providing education to disabled children. The number of schools that have been opened under this program are, 1,60,000 and 84,000 alternative schools. Furthermore, planning is implemented for the construction of 52,758 schools. The disabled students that have been enrolled in schools are, 4,20,203.

National Program for Nutritional Support to Primary Education

This program was initiated on $15^{\text {th }}$ August, 1995 with the main objective of increasing enrolment, retention and attendance in primary schools by providing nutritional meals to children. The outcomes of this scheme has been positive. By 1997-1998, the scheme was introduced in all blocks of the country. The number of children covered accounted for around 110 million. It is implemented for the students, belonging to classes, I-V. It was further extended in 2002 , to cover the children, studying in the centres, operated under the Education Guarantee Scheme (EGS) and Alternative and Innovative Education Scheme (AIE). The central assistance under the scheme included, free supply of food grains, i.e. 100 grams per child per school day and subsidy for transportation of food grains up to a maximum of Rs. 50,000 per quintal [4].

\section{Operation blackboard}

One of the important objectives of educational development is Universalization of Elementary Education. Making provision of free and compulsory education to all children, up to the age of 14 years is included in the guiding principles of Indian Constitution and is also a part of the Minimum Needs Program and 20-Point Program. The primary objective in the educational policy, declared by the central government in 1986, was making provision of free and compulsory education to all children, up to the age of 14 years by 1995. Operation Blackboard is the scheme formulated to achieve the goal [5]. This scheme was initiated in 1987 with the main objective of bringing about improvements in the school environmental conditions. Another important area that was taken into consideration was retention and augmentation of academic skills among the students. This program has led to improvements in primary education to a large extent. During the initial stage, the number of schools covered were 5,23,000.

\section{Recommendations}

Education is regarded as the key to alleviate poverty and backwardness. The school going children within rural communities are also residing in the conditions of poverty. Due to the prevalence of the conditions of poverty, they are compelled to work and not get enrolled in schools [6]. The value of education has been comprehensively recognised among rural individuals [7]. They aspire to get their children enrolled in schools, but when they are overwhelmed by the conditions of poverty or experience severe financial problems, then they are regarded as major impediments within the course of acquisition of education. The recommendations for bringing about improvements in rural education and encouraging the families as well as the students to get enrolled in schools have been stated as follows:

- The specialists and the professionals, who are involved in rural development need to conduct an analysis of the rural environmental conditions. Both physical and cultural environmental conditions need to be taken into account. When the designing and implementation of the projects takes place, then it is vital to ensure that the environmental conditions will be able to cope up with the projects in an appropriate manner [8].

- The communities should be encouraged to use the schools as the centre for education and social activities, beyond the primary schools. The school environmental conditions should be made hospitable for the organization of adult literacy classes, extension activities, women's groups, community functions and other activities and events. In this manner, the school gets transformed into a multi-function learning or a meeting centre [8].

- The parents and teachers should get involved into interaction with each other on a timely basis. This interaction would facilitate effective learning and augmentation of skills and abilities among the students. When students experience setbacks in their performances, then parents as well as the teachers can provide each other suggestions, with the common purpose of generating good academic outcomes on the part of the students.

- Within some schools, there are provision of mid-day meals, whereas in some, students are required to bring their meals from homes. But in most of the rural schools, there is lack of civic amenities, such as, restrooms and clean drinking water. The students normally are required to stay in schools for 
around five to six hours. Hence, it is of utmost significance for the schools to provide basic civic amenities for the students, as well as for teachers and staff members.

- The schools should provide the resources for teaching students regarding the rural environment, agricultural skills and other practical skills and knowledge. The teachers should train students in terms of preservation of the environment and how to keep the environment clean. The rural communities are normally dependent upon the natural environmental conditions. Hence, they need to be aware of methods and strategies, in terms of its preservation.

- Appreciating the efforts of students is also regarded as an important aspect, mainly to arouse interest and enthusiasm among them towards learning. For this purpose, rewards and scholarships are provided to the students in various forms. These include, giving of stationary items, bags, food items or monetary resources. Appreciation and rewards leads to an increase in the retention of students in schools and decline in the rate of absenteeism.

- There are number of children within rural communities, who are unable to attend schools, due to lack of transportation facilities. Therefore, in order to increase the enrolment of students in schools, it is vital to make provision of transportation facilities. When there will be availability of buses, then large number of students will easily be able to transfer to school and back home. This would lead to an increase in enrolment and decline in the rate of absenteeism.

- In rural schools, apart from providing knowledge and information to the students in terms of academic skills, it is necessary to organize activities and picnics. In the organization of activities and picnics, it is vital to ensure that students are able to acquire an efficient understanding of the academic concepts, as well as take pleasure in participation. This would lead to an increase in the retention rate of students.

- Implementation of policies and rules among schools is an essential aspect. When educational institutions are established within rural communities, then it is essential to ensure that adequate policies and rules are formulated. Policies and rules would make the individuals disciplined. These would not only enable the individuals to carry out their job duties in an appropriate manner, but also inculcate the traits of morality, ethics, righteousness and honesty among themselves.

- In rural schools, girls have experienced various forms of criminal acts too, such as, sexual harassment, verbal abuse, and dis- criminatory treatment. Hence, policies should be formulated that would enable the girls to feel comfortable within the school environment. Equal rights and opportunities should be provided to them and they should be communicated with respect and courtesy. Furthermore, there should not be any kind of discrimination on the basis of caste, creed, race, religion, gender, age, ethnicity and socio-economic background.

\section{Conclusions}

Education is regarded as an instrument that leads to effective growth and development of the individuals and enable them to sustain their living conditions adequately. The system of rural education is not in a well-developed state and there are number of problems associated with it. These include, unsatisfactory teaching-learning methods, lack of transportation facilities, lack of infrastructure, lack of extra-curricular activities, lack of financial resources, absence of competitions and events, shortage of teachers, low income, conflicts and disputes and discriminatory treatment. The lack of resources is one of the major problems, which include, financial resources and human resources. Due to lack of resources, schools are experiencing problems in making advancements in the system of education. These problems and challenges are imposing number of unfavourable effects upon the students. As a result of these problems, there is a decline in the retention rate of the students, increase in the rate of absenteeism, and girls, when experience discriminatory treatment or any form of criminal act, usually drop out, before their educational skills are honed.

There is a need to formulate measures for bringing about improvements in the system of rural education. These are, up-gradation of teaching-learning methods, use of technology, organization of workshops, implementation of extra-curricular activities, implementing proper evaluation procedures, rewarding students, providing adequate infrastructure, financial assistance, equal opportunities, and organization of classes for the parents. When these measures would be put into operation in an appropriate manner, then improvements would be bought about in the system of rural education. There have been programs formulated by the government for bringing about improvements in rural education. These are, Lok Jumbish Project (LJ), Shiksha Karmi Project (SKP), Sarva Shiksha Abhiyan (SSA), District Primary Education Program (DPEP), National Program for Nutritional Support to Primary Education and Operation Blackboard. With the initiation of measures and programs on the part of the government, non-government organizations and other agencies, there have been improvements made in the system of rural education. The Right to Education Act (2009) makes provision of free and compulsory education to all children, belonging to the age group of six to fourteen years. 


\section{Bibliography}

1. Sreekanthachari JG and Nagaraja G. "An Overview of Rural Education in India". Advance Research Journal of Social Science 4.1 (2013): 115-119.

2. Roy NK. "ICT-Enabled Rural Education in India". International Journal of Information and Education Technology 2.5 (2012): 525-529.

3. Ramachandran V. Lok Jumbish - Rajasthan People's Movement for Education for All. The World Bank, New Delhi (2003).

4. National Programme of Nutritional Support to Primary Education. Ministry of Human Resource Development. Department of School Education and Literacy (2006).

5. Operation Blackboard Scheme (1995-96).

6. Shahapur NP and Omprakash HM. "Rural Education in India: A Scenario". Scholarly Research Journal for Interdisciplinary Studies 4.31 (2017): 5268-5272.

7. Motiram S and Osberg L. "Demand or Supply for Schooling in Rural India?".

8. Moulton J. "Improving Education in Rural Areas: Guidance for Rural Development Specialists” (2001).

Volume 3 Issue 7 July 2019

(c) All rights are reserved by Radhika Kapur. 